\title{
Review of Hole Cleaning in Complex Structural Wells
}

\author{
Sun Xiaofeng*, ${ }^{*}$, Wang Kelin ${ }^{1}$, Yan Tie ${ }^{1}$, Zhang Yang ${ }^{2}$, Shao Shuai ${ }^{1}$ and Luan Shizhu ${ }^{1}$ \\ ${ }^{I}$ College of Petroleum Engineering, Northeast Petroleum University, Daqing, Heilongjiang, China; ${ }^{2}$ Research Institute \\ of Oil and Gas Engineering, Tarim Oilfield, Korla, Xinjiang, China
}

\begin{abstract}
Complex structural wells are widely used in the development of marine oilfield, old oilfield and low permeable oilfield. However, poor hole cleaning is often occurred in the highly-deviated sections and horizontal sections of the complex structural wells, which affects rate of penetration and downhole safety.

The methods to study cuttings transport can be normally divided into four types: 1) experimental observations, 2) CFD simulations, 3) theoretical correlations and models and 4) field tests. Experimental observations and CFD simulations are mainly used to analyze the effects of different parameters on hole cleaning and obtain some valuable data. Theoretical models and correlations are mainly applied to calculate cuttings bed height, critical velocity and etc to provide the guidance for the design of hydraulic parameters. The accuracy of the first three types are checked by field tests. In this paper, the effects of flow rate, inclination, mud rheology, drillpipe rotation and other factors on hole cleaning, and some typical correlations and models were briefly reviewed before 2000 years, and some new research findings were detailedly addressed. In addition, CFD simulations also were introduced.
\end{abstract}

Although major improvements have been achieved in the past several decades, building a comprehensive and proven model requires much more experimental researches, CFD simulations, in-depth theoretic studies and field tests due to the complexity of cuttings transport under multi-factor interactions.

Keywords: Hole cleaning; cuttings transport; complex structural well.

\section{INTRODUCTION}

Complex structural wells, including extended reach well, horizontal well, multilateral well, and etc are widely used in the development of marine oilfield, old oilfield and low permeable oilfield. However, poor hole cleaning is often occurred in the highly-deviated sections and horizontal sections of the complex structural wells, which seriously affects rate of penetration and downhole safety. In recent years, despite many measures taken to control hole cleaning, the accident still happened from time to tome. For example, in the extended reach well of Xijiang 24-A14 in the South China Sea, hole cleaning problem led to more than one sticking, and the drill string was jammed in 10328 feet and 11225 feet respectively [1]. The poor hole cleaning also happened the $8 \frac{1}{2}$ inch section of extended reach wells in BP's Wych Farm Oilfield [1]. However, the average stuck pipe cost per well amounted to 1.7 million dollars for each well drilled between 1985 and 1988 [2]. For a long time, many scholars has been studying the hole cleaning problems of complex structural wells, and some achievements were made. Considering some major achievements reviewed by Pilehavri et al. [3], this paper made a brief summary of hole cleaning before 2000 years, and the latest experimental researches, CFD simulations, correlations and models, and future study needs in hole cleaning were mainly addressed.

*Address correspondence to this author at the College of Petroleum Engineering, Northeast Petroleum University, Daqing 163318, Heilongjiang, China; Tel: 0459-6503521; Fax: 0459-6503482;

E-mail: suneye@126.com

\section{EXPERIEMNTAL RESEARCH ON HOLE CLEAN- ING}

In order to analyze the effect of different parameters on hole cleaning and observe cuttings transport mechanism, besides TUDRP, Heriot-Watt University, BP, Southwest Research, M.I. Drilling Fluids and the Institute of Francais du Petrole described by Pilehavri et al. [3], JNOC [4], BJ Services [5], METU [6] and China University of Petroleum [7] also established flow loops.

Table 1 lists some typical experimental researches on hole cleaning before 2000 years. The Table indicates fluid flow rate, mud rheology, inclination, pipe rotation, ROP, particle size, pipe eccentricity, mud density have a certain effect on cuttings transport, and multi-factor interactions also were observed. In addition, the effect of fiber sweep on hole cleaning was studied by many experiments [8-10].

\subsection{The Effects Mud Rheology, Particle Size and Drillpipe Rotation on Hole Cleaning}

As shown in Table 1, the effect of mud rheology, particle size and drillpipe rotation on cuttings transport may be dependent on other factors, which leads to the complexity of observations and may reach some different conclusions. Therefore, mud rheology [20-24], particle size [20, 21, 23, $25,26]$, and drillpipe rotation $[6,24,27]$ continued to be studied.

Li et al. [20] studied the effects of fluid rheology and particle size on cuttings transport in coiling operations. The experiments were conducted with a BJ Services'5 inch 20 feet long flow loop. The study on fluid rheology indicates: 1) 
Table 1. Experimental analysis of major parameters on hole cleaning before 2000 years.

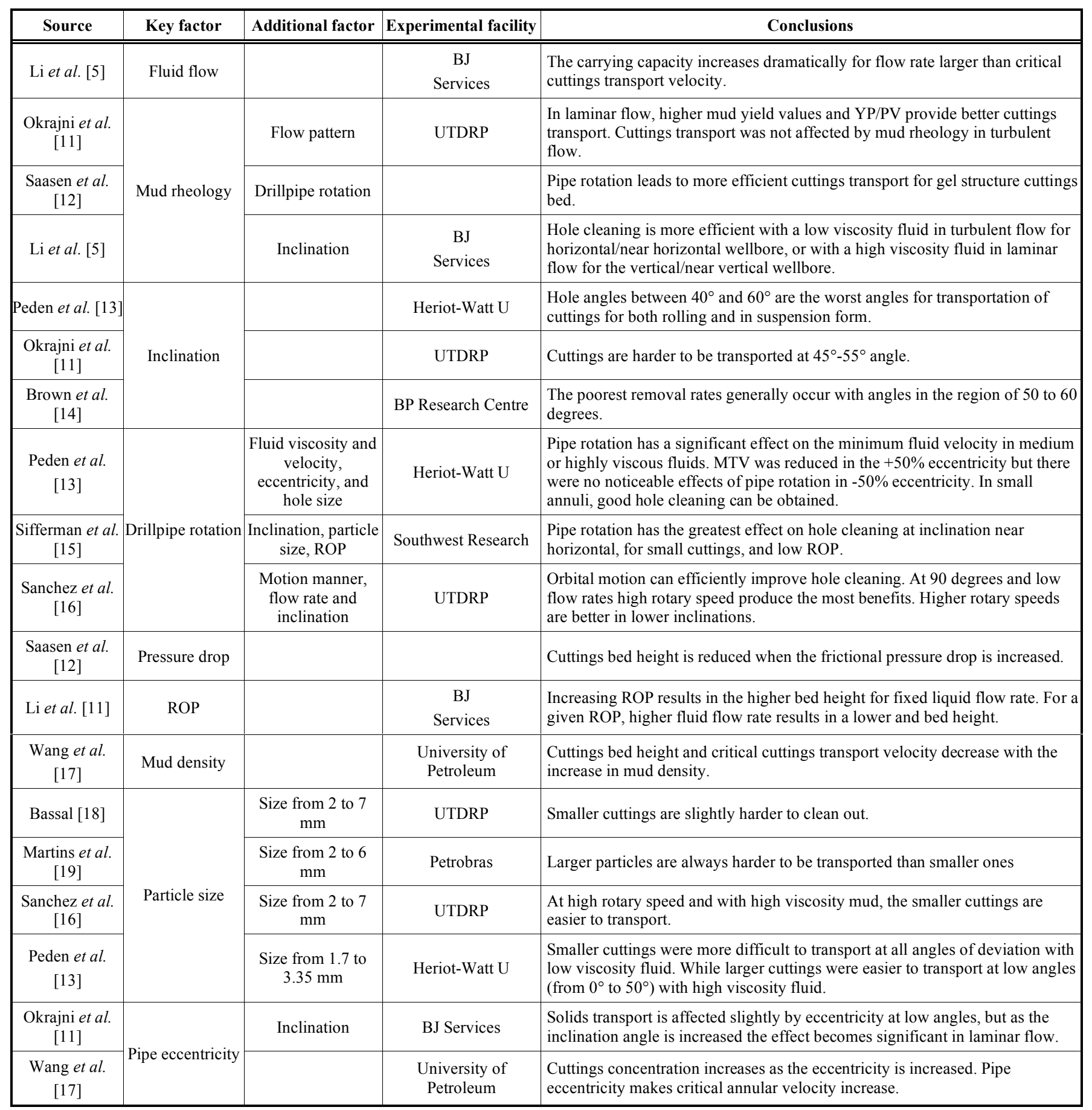

In horizontal sections, Xanvis and HEC polymer based fluids are more effective than water in terms of carrying capacity but cannot erode a stationary. 2) For the vertical/near vertical wellbore, hole cleaning is more efficient if a high viscosity fluid is pumped in a laminar flow regime rather than a low viscosity fluid in turbulent flow. 3) Xanvis polymer with a 20lb/1000gal loading has excellent solids carrying capacity and is efficient for hole cleaning up to 60 degrees. In addition, for the tested particle size range from 0.15 to $7 \mathrm{~mm}$, an average size of $0.76 \mathrm{~mm}$ poses the greatest difficulty for solids transport with the water. The conclusion is consistent with Martins et al. [19] with the Xanvis.
Duan et al. [25] focused on studying three sizes of cuttings $(0.45 \mathrm{~mm}-3.3 \mathrm{~mm})$ with TUDRP's 8 inch 100 feet flow loop. These experiments were conducted with water and polymeric fluids. The results indicate smaller cuttings is more difficulty to be removed than larger cuttings when tested with water. However, when tested with 0.25 ppb PAC solutions, the smaller cuttings is easier to be transported. Also, pipe rotation and fluid rehology were the key factors in controlling small cuttings transport.

In addition, Duan et al. [26] still conducted experiments to determine the critical resuspension velocity (CRV) and the 
critical deposition velocity (CDV) for $0.45 \mathrm{~mm}$ and $1.4 \mathrm{~mm}$ sands in different fluids over a range of bed heights and inclination. It was reported that depending on sand size and fluid properties, CDV is approximately two to three times larger than CRV. Also, water is more effective than lowconcentration polymer solutions for bed erosion, but polymer solutions are more helpful than water in preventing cuttings bed formation.

Ozbayoglu et al. [6] observed specifically the effect of drillpipe rotation on hole cleaning using a 3 inch 12 feet long METU's flow loop. It was observed drillpipe rotation has a significant improvement on cuttings transport, especially making an orbital motion, and drastically decreases the critical velocity required to remove stationary cuttings bed totally. However, drillpipe rotation has no an additional contribution to hole cleaning after a certain rotation speed.

In METU's flow loop, Sorgun [24] also analyzed the effect drillpipe rotation. The result indicates pipe rotation significantly decrease cuttings bed thickness and critical fluid velocity required to prevent stationary bed development for both water and drilling fluids, especially if the pipe is fully eccentric position. However, after a certain pipe rotation speed, no additional contribution of pipe rotation is observed on critical velocity. In addition, for no-rotation and low rotation case, an increase in mud viscosity decreases Reynolds Number and the carrying capacity of drilling fluids, but this effect diminishes as the pipe rotation speed is increased.

\subsection{The Effects of Fiber Sweep on Hole Cleaning}

For horizontal and highly deviated sections, using fiber sweep can be helpful for cleaning the borehole and reducing cuttings-bed thickness. Some field applications were also conducted, and made some achievements [28, 29]. However, the flow behavior, hydraulics, and cuttings-transport efficiency of fiber sweeps is less known, and some experiments [8-10] about fiber sweep were conducted.

Valluri et al. [8] investigated the effect of rheology of the sweep fluid on sweep efficiency under LPAT and elevated temperature elevated pressure (EPET) conditions. The LPAT experiments were conducted on an 8 inch 90 feet long TUDRP's flow loop. The EPET experiments were performed on a TUDRP's 5.76 inch 73 feet long flow loop. These studies show in the absence of drillpipe rotation, highviscosity and high-density sweeps were found to be ineffective in a horizontal configuration, and temperature could affect the sweep efficiency by changing the rheological properties of drilling fluid.

Ahmed et al. [9] conducted hole cleaning performance of a fiber sweep in a 2 inch 12 feet long flow loop. Comparing the fiber sweep $(0.47 \%$ Xanthan gum $(\mathrm{XG})$ with $0.04 \%$ synthetic fiber) with the base fluid $(0.47 \% \mathrm{XG})$ indicates fiber sweep has better hole cleaning capabilities than the base fluid in the horizontal configuration. When tests are conducted in an inclined configuration ( $68^{\circ}$ from vertical), improvement in the hole cleaning capability of the fluid due to the addition of fiber is moderate.

Cheung et al. [10] also carried out experiments with different drillpipe rotation speeds (0 to $90 \mathrm{rpm}$ ) and fiber concentrations $(0 \%, 0.05 \%, 0.1 \%$, and $0.2 \%$, by weight $)$ in TUDRP 's small indoor flow loop. The results indicate an increase in fiber concentration improves the hole cleaning efficiency with high pipe rotation or flow rate. As a greater amount of fiber were employed, efficiency further decreased, unless combined with adequate pipe rotation or flow rate.

\subsection{The Effects Other Parameters on Hole Cleaning}

Besides the above analyzed factors, flow rate, inclination, critical velocity and other parameters also were investigated by many experiments [20, 21, 23, 30-32].

Ozbayoglu et al. [21] performed extensive experiments to analyze the effects of major parameters on cuttings transport efficiency in an 8 inch 100 feet long TUDRP Low-Pressure Ambient-Temperature (LPAT) flow loop. It was reported that average annular velocity is the dominating parameter on hole cleaning, and turbulent flow is the better for preventing bed development. Also, cuttings properties, fluid density, inclination and eccentricity have some effects on the cuttings transport. They [30] still studied the critical velocity with a 4 inch 15 feet long METU flow loop. The results show that the stationary bed is developed when the flow rate is less than 6 $\mathrm{ft} / \mathrm{sec}$, and a critical flow rate of $8 \mathrm{ft} / \mathrm{sec}$ is required to establish a no-bed condition.

Besides the analysis of drillpipe rotation and mud rheology, Sorgun [24] still studied the fluid velocity, ROP and inclination. The results show stationary cuttings bed thickness decreases drastically for all drilling muds as the fluid velocity increases. After a certain fluid velocity, stationary bed is removed from the wellbore. Inclination has a slight effect on cuttings bed thickness inside annulus between $60^{\circ}$ to $90^{\circ}$ for all mud systems without pipe rotation. When the fluid velocity is $0.95 \mathrm{~m} / \mathrm{s}$ and flow horizontal annulus, no significant change in cuttings bed thickness is observed as the rate of penetration is increased.

Kelessidis et al. [31] analyzed the effects of hydraulic parameters on cuttings transport in a $70 \mathrm{~cm} 5 \mathrm{~m}$ long flow experimental facility. Experiments were performed with water and aqueous solutions of Carboxy-Methy1-Cellulose (CMC). Test results were based on visual observation and on video and photos taken. They reported the moving bed at low rate can be eroded with increase in flow rate. At higher flow rate, but not sufficiently high for full suspension, the solids don't deposit on the wall but flow in streaks near the bottom wall of the annulus.

Masuda et al. [32] conducted experiments to determine the critical cuttings transport velocity with a 5 inch 8 feet long JNOC's flow loop. The behavior of cuttings at both steady-state and unsteady-state flow conditions were recorded by a CCD video camera system. The data acquisition system, based on a sophisticated image analysis system, enables the cuttings concentration and cuttings velocity to be estimated.

\section{CFD SIMULATIONS ON HOLE CLEANING}

CFD can eliminate the need for expensive laboratory setups and be used to simulate a unlimited number of physical and operational conditions in any wellbore. It helps the researchers get to the root of problems and can provide enough information that measurements are either difficult or 
Table 2. Theoretical models about hole cleaning before 2000 years.

\begin{tabular}{|c|c|c|c|c|c|}
\hline Source & Main goal & Model type & Main factors & $\begin{array}{c}\text { Time- } \\
\text { dependent }\end{array}$ & Applicability \\
\hline $\begin{array}{l}\text { Gavignet et al. } \\
\text { [41] }\end{array}$ & Bed height & Pure fluid layer and cuttings bed & $\begin{array}{l}\text { Mud rheology, eccentricity, } \\
\text { inclination }\end{array}$ & No & Deviated wells \\
\hline $\begin{array}{c}\text { Santana et al. } \\
\text { [42] }\end{array}$ & Bed height & Suspension layer and cuttings bed & Solid-liquid slip & No & $\begin{array}{l}\text { High angle and horizontal } \\
\text { wells }\end{array}$ \\
\hline $\begin{array}{c}\text { Martins et al. } \\
{[43]}\end{array}$ & Cuttings concentration & Suspension layer and cuttings bed & Diffusion equation & No & $\begin{array}{l}\text { Horizontal and near } \\
\text { horizontal wells }\end{array}$ \\
\hline $\begin{array}{c}\text { Nguyen et al. } \\
\text { [44] }\end{array}$ & Bed height & $\begin{array}{l}\text { Pure fluid layer, mobile cuttings bed and } \\
\text { static cuttings bed }\end{array}$ & Effective thickness expression & No & $\begin{array}{l}\text { Deviated and horizontal } \\
\text { wells }\end{array}$ \\
\hline Martins [45] & Bed height & Suspension layer and cuttings bed & $\begin{array}{l}\text { Gain/loss from crumbling, cave- } \\
\text { in of wellbore }\end{array}$ & Yes & $\begin{array}{l}\text { Extended } \\
\text { reach wells }\end{array}$ \\
\hline $\begin{array}{c}\text { Kamp et al. } \\
{[46]}\end{array}$ & Bed height & Suspension layer and cuttings bed & Cuttings settling and resuspension & No & Highly inclined wells \\
\hline $\begin{array}{l}\text { Ford et al. } \\
\quad[47]\end{array}$ & $\begin{array}{l}\text { Minimum transport } \\
\text { velocity }\end{array}$ & & Cuttings suspension and rolling & & Deviated wells \\
\hline $\begin{array}{l}\text { Clark et al. } \\
\quad[48]\end{array}$ & $\begin{array}{l}\text { Minimum transport } \\
\text { velocity }\end{array}$ & & Settling, lifting and rolling & & $\begin{array}{c}\text { From vertical to horizontal } \\
\text { wells }\end{array}$ \\
\hline
\end{tabular}

Table 3. Correlations about hole cleaning before 2000 years.

\begin{tabular}{|c|c|c|c|}
\hline Source & Main goal & Considering factors & Applicability \\
\hline \hline Larsen et al. $[49]$ & Critical transport fluid velocity & ROP, particle size, inclination, mud rheology and density. & From $55^{\circ}$ to $90^{\circ}$ \\
\hline Luo et al. $[50]$ & Critical flow rate & $\begin{array}{c}\text { Annular size, eccentricity, Gravitational force, inclination, flow } \\
\text { rate, fluid and cutting properties. }\end{array}$ & Deviated wells \\
\hline Wang et al. $[14]$ & Bed height & $\begin{array}{c}\text { Pipe rotation, annular velocity, mud density and viscosity, } \\
\text { eccentricity, injected cuttings volume. }\end{array}$ & Horizontal wells \\
\hline
\end{tabular}

impossible to obtain. Since Bilgesu et al used CFD for cuttings transport, some people [24, 33-38] were trying using CFD to simulate the effects of different factors on hole cleaning, and others [39, 40] designed the cuttings bed tool and analyzed the relevant parameters of the tools.

Bilgesu et al $[33,34]$ was one of the first researchers to analyze cuttings transport parameters using CFD. The simulations show drillpipe rotation can improve the cuttings transport but the effect is more pronounced for smaller particle size. Cutting transport efficiency has a decreasing trend with increase in annular velocity. In addition, inclination and ROP also have major impacts on cuttings concentration.

Ali et al. [35] performed the parametric study of CFD on cuttings transport in horizontal and vertical wells. The parameters affecting cuttings transport were classified into four groups, mud weight, cutting size, mud viscosity and ROP. The simulations show: 1) The best way is to cuttings transport with a low viscosity fluid in turbulent flow but to maximize the carrying capacity a high density mud should be used. 2) An increase in mud flow rate at higher mud density greatly improves the cuttings transport. 3) Cuttings transport for small particle size is greatly enhanced when drilling with high density mud circulated at high flow rate for the $0.1,0.175$ and 0.275 in. particles. 4) Cuttings transport increases as viscosity increases. 5) ROP has a significant effect on cuttings transport at low circulation rate.
Mishra [36] used the Eulerian Model in CFD program to simulate the cuttings transport. The simulations indicate it becomes harder to remove particles as the inclination decreases. Larger particles are easier to be removed by water, and are remarkably affected by increasing flow rate. The initial flow rate used for horizontal wells lead to blockage of the annular section in deviated wells. In addition, drillpipe rotation has the same conclusion with Bilgesu et al. [33, 34].

Li et al. [37, 38] studied the effect drillpipe rotation on hole cleaning in horizontal wells with CFD. The physical model was that $215.9 \mathrm{~mm}-127 \mathrm{~mm}$ annulus, 0.5 eccentricity and $20 \mathrm{~m}$ length. The simulations indicate: 1) Drillpipe rotation drives fluid and solid circumferential motion. 2) Helical motion is the main manner for fluid and solid. 3) Drillpipe rotation not only reduces solid concentration in annulus, but also makes cuttings accelerate. 4) Particles distribution are asymmetrical in annulus. 5) Rotation speed between 80 and $120 \mathrm{rpm}$ has a significant effect on cuttings bed.

Sun [39] simulated the velocity field, pressure and trace of fluid for cuttings bed removal tool using CFD. It was observed V-shape slot can make velocity field helical distribution and inlet velocity increase by around 100\% in a very short axial distance. Especially, velocity increases the most at the bottom of the tool, which leads to more efficient cuttings transport. 
Chen et al. [40] used CFD to analyzed the mechanism of an effective hydroclean drillpipe (EHCDP) for hole cleaning. The flow diagrams, velocity field and pressure field of EHCDP were simulated by examining the effect of a spiral grooves structure on flow behaviors of the annulus fluid. The results show fluid can form a vortex cavity near spiral grooves with EHCDP, and cuttings are transported by the vortex cavity from low side to up side. In addition, drillpipe rotation produces the centrifugal force, which makes cuttings thrown into the up side of annauli.

\section{CORRELATIONS AND MODELS OF HOLE CLEANIG}

Through experimental observations and CFD simulations, we can better observe and understand cuttings transport process. To describe cuttings-transport efficiency quantitatively, a large number of correlations (Table 3) and models (Table 2) were developed, and two types of parameters were used as target variables. The first type indicates the amount of annular cuttings under a given drilling condition, and can be calculated by annular cuttings correlations and models. The second type shows the required annular velocity to keep a minimum a amount of cuttings in a well, and can be got from the annular critical velocity correlations and models.

\subsection{The Annular Cuttings Correlations and Models on Hole Cleaning}

The amount of annular cuttings can clearly reflect the cuttings transport efficiency. In previous studies, equivalent cuttings bed height $[14,25,41,42,44-46]$, cuttings concentration [25, 43], annular bed area [50], and the ratio between mass of suspended particles and initial mass of deposited cuttings [27] can be used to depict the amount of annular cuttings. As shown in Table $\mathbf{2}$ and Table 3, even more factors such as mud rheology, cuttings concentration were considered in some correlations and models, complexity of cuttings transport leads to the big gap between theoretic studies and real drilling conditions. Therefore, steady layer models [51, 55], transient models [32, 56-60], multi-region models [61, 62], correlations $[25,37,38,63]$ constantly appeared in the recent years.

According to Nguyen et al. [44] theory, cuttings transport will be two-layer flow pattern in high flow rate. Based on the steady state condition, Cho et al. [51] developed two-layer model neglecting reservoir inflow and outflow. The model ignored the slip between the solid and liquid, drillpipe rotation and solid-liquid interaction. It was applied to identify the effects of fluid flow in porous cuttings-bed and the differences of relative velocities between cuttings and carrier fluid on drilling hydraulics in coiling operations. Considering the similar factors, the model proposed by Wang et al. [52] can be applied to calculate the cuttings bed height and pressure drop in different conditions.

As the flow rate is decreased, stationary cuttings bed begins to appear, and Cho et al. [53] presented three-layer flow of solid-liquid mixture concept to predict cuttings bed mechanism in coiling drilling. The model analyzed forces acting on the each layer, and considered reheology, cuttings size/sphericity/ concentration, wellbore geometry, eccentricity and flow rate.
Considering the wide range of flow rate, cuttings transport may be fully suspended symmetric flow, asymmetric flow, moving bed flow, three-layer flow or full blockage. Kelessidis et al. [54] combined two-layer model and three-layer model to cover all the flow patterns.

In most cases, vertical section and near vertical section, transient section and horizontal to near horizontal section exist together, and cuttings transport is a continuous process in drilling process. A three-segment hydraulic model developed by Cho et al. [55] can cover all the sections. According to the characteristics of cuttings bed, the model made the well divide into three sections with $30^{\circ}$ and $60^{\circ}$. The two-layer model was applied for transient section, and the three-layer model was used for the horizontal to near horizontal section.

The above models were developed based on steady state condition, and didn't depict the formation of cuttings bed. Li et al. [56] presented 1D transient cuttings transport model with conventional drilling fluids. The model considered the slippage between drilling fluid and cuttings, and could be used to predict cuttings bed height as a function of drilling fluid flow rate, rheology, drilling rate wellbore geometry and drillpipe eccentricity. Besides the slip between solid and fluid, solid-liquid interaction was considered in the transient model proposed by Suzana et al. [57]. The model was to simulate the cuttings bed height, pressure, cuttings concentration and ECD over the whole trajectory of the well.

Based on Martins et al. model [45], Wang et al. [58] introduced the diffusion equation into the two-layer timedependent model. Later, they [59] made the cuttings bed divided into mobile and stationary cuttings bed. In addition, drillpipe rotation was used to modified the suspension layer velocity, and cuttings transport in the form of suspension, rolling, slipping, or all these forms together was considered. The dynamics thickness of cuttings bed can be predicted by measured ECD, giving a guideline to cuttings bed monitor and control for ERW drilling, and which has been successfully used in oil field of South China Sea.

The transient model proposed by Doan et al. [60] can simulate the cuttings transport of an annulus of arbitrary eccentricity and include cuttings deposition and resuspension, formation, and movement of cuttings bed. The interaction between fluid phase and solid phase in suspended layer, and interaction between cuttings bed and suspended layer were incorporated.

Besides layer models, the two-region system composed of a fluid bed and a stationary bed was introduced by Espinosa-Paredes et al. [61], and the averaging method was used to analyze it. The averaging pressure drop and averaging velocity were solved numerically by using the finite-difference technique in the implicit scheme, and the results agree well with experimental data. Salazar-Mendoza [62] considered at the bottom of the horizontal pipe a region made with a stationary cuttings bed based on EspinosaParedes et al. [61] model, and developed three-region system for cuttings transport. However, the two models is difficulty to be solved for cuttings bed height or cuttings concentrations. 


\subsection{The Annular Critical Velocity Correlations and Models on Hole Cleaning}

To assure the safe and efficient drilling, the reasonable choose of flow rate and accurate prediction of critical velocity are very important. In the studies, besides critical transport fluid velocity (CTFV), critical flow rate (CFR), and minimum transport velocity (MTV) in Table $\mathbf{2}$ and Table $\mathbf{3}$, $\mathrm{CRV}, \mathrm{CDV}$ and minimum flow rate are also used to depict the critical velocity. All of these names show the same condition which is defined as the minimum average annular fluid velocity to prevent the formation of cuttings bed.

Zhao et al. [64] studied on the critical velocity for particle incipient motion considering the randomness of particle location. A random variable of dimensionless submergence was introduced to denote the location randomness, and the critical correlation was built by means of moment equilibrium analysis. The results of the correlation have a good agreement with the experimental data for the particle with diameter range from $0.001 \mathrm{~mm}$ to $10 \mathrm{~mm}$.

Duan et al. [26] developed a mechanistic to predict CRV for a solid bed. The model accounts for drillpipe eccentricity in any direction in an annulus, and is consistent with experimental observations. In addition, existing CDV correlations developed for larger cuttings were verified by experimental data, and the differences are approximately $25 \%$.

Ozbayoglu et al. [63] conducted extensive experiments to develop the empirical correlation for calculating estimate the critical velocity to prevent development of a cuttings bed. The inclination, ROP, annular size, mud viscosity and density were considered. But the correlation is only suitable for fully eccentricity and no drillpipe rotation.

Mohammadsalehi et al. [65] combined Larsen model [49] and Moore's correlation, and developed the correlation of the minimum flow rate for all range of inclination namely from $0^{\circ}$ to $90^{\circ}$. The results show behavior of flow rate selection varies by well inclination. Within the range of $0^{\circ}$ to $55^{\circ}$, as the rheological of drilling fluid goes higher the valve for required flow rate decreases, and the major acting on cuttings can be overcome by increase fluid carrying capacity. Within high inclination intervals, lower rheological properties of drilling fluid is more desirable and produce better hole cleaning effects.

\section{FUTURE RESEARCHES AND RECOMMENDA- TIONS}

\subsection{Improving Flow Loops}

Even though many flow loops have been established in the past several decades, most of these flow loops can not depict the real cuttings transport under downhole conditions, such as formation fluid influx, wellbore collapse and the change of annular temperature. Meanwhile, these facilities only can measure cuttings bed height or area and pressure, and can't record velocity field and concentration distribution of particle, which leads to the bad accuracy of some coefficients referred by mechanistic models and affects the accuracy of mechanistic models. Ideally, CCD video camera system $[27,32]$ is introduced into flow loops to record the velocity profile, cross-sectional distribution and average velocity of cuttings. Also, a more real annular tested section should be considered to accord with the different downhole conditions.

\subsection{Improving Mechanistic Models}

There seems to be two main reasons for a low accuracy of most of mechanistic models. First, researchers used the same methodology for different physical phenomena that occur under different conditions. The other problem is to apply the improper concepts, simplify too many assumptions or neglect certain observed phenomena [53]. When drillpipe is rotating and cuttings bed is thin, cuttings bed distribution is different from the existing model [66]. Therefore, a new theory or method will be introduced into mechanistic model. In addition, different rheology of fluid, particle shape, cuttings bed concentration and other parameters will be gradually considered, and some high-accuracy coefficients can be obtained from the advanced flow loop.

\subsection{Developing Cuttings Bed Removal Tool}

Over the years, chemical method involve addition of drilling-fluid addictives, such as viscosities and weighting agents, but these methods are inefficient in completely preventing the formation of the cuttings bed. Meanwhile, these methods affects the characteristic of drilling fluid, especially for high-temperature high-pressure wells, which may cause drilling accident. Compared with these methods, cuttings bed removal tool has two advantages of no effect on the characteristic of drilling fluid and ease of use. Different type of tools $[1,39,40,67,68]$ have been studied over several decades, and VAM Drilling [69] has released two generation products and conducted commercial applications. However, how to realize that cuttings bed is removed and the frictional resistance is reduced is still a difficulty challenge.

\subsection{Building Hole Cleaning Monitoring System}

In order to better deal with the hole cleaning problems in complex structural wells, the monitoring system can be built. The system should be composed of data collecting system, data processing system and measure prompting system. Data collecting system uses advanced instruments to rapidly collect the available data such as rotary speed of drillpipe, annular fluid flow rate, drillpipe friction and ECD. Subsequently, the system can obtain the real-time hole cleaning conditions and related downhole safety problems by processing these data. Meanwhile, the next-time hole cleaning conditions are also predicted to make a high-speed decision whether measures are taken to prevent downhole accidents. Martins et al. [70] make such an attempt, but much more work is needed to built a comprehensive monitoring system.

\subsection{Recommendations}

Based on extensive studies of cuttings transport and field experiences, the following suggestions are recommended to achieve better hole cleaning and cuttings transport.

(1) Hole cleaning problem should be integrated into hydraulics design before drilling.

(2) Critical inclination is avoided in the well path design if possible [3]. 
(3) If possible, top drive rigs and drilling fluid continuous circulation system can be used to keep drillpipe rotation and drilling fluid circulation while tripping.

(4) High flow rate, good mud rehology and cuttings bed removal tool can be used together. If there is poor hole cleaning, the double pump is applied to erode cuttings bed with low viscosity fluid.

(5) Low viscosity drilling fluids for loose formation drilling and polymeric drilling fluids for hard formation drilling can realize efficient cuttings transport.

(6) When adjusting drilling fluid performance, annular flow should be considered.

(7) Solids control system will continue working to keep lower solid concentration and sand content.

\section{CONFLICT OF INTEREST}

Declared none.

\section{ACKNOWLEDGEMENTS}

The support of National Science and Technology Major Project of China (No. 2011ZX05009-005) and the National Natural Science Foundation of China (No. 51174043, No. 51204056) are gratefully acknowledged.

\section{REFERENCES}

[1] C.S. Lu, "Numerical Calculation of Cuttings Transportation in Inclined Borehole and Flow Field Calculation of Cuttings Removing Tool", China University of Petroleum (East China), Dongying, China, 2008.

[2] W. B. Bradley, D. Jarman, R. S. Plott, R. D. Wood, T. R. Schofleld, R. A. Aufllck, and D. Cooking, A Task Force Approach to Reducing Stuck Pipe Costs, at the 1991 SPE/IADC Drilling Conference, 1991, pp. 841-846.

[3] A. A. Pilevhavari, J. J. Azar, and S. A. Shirazi, "State-of-the-art cuttings transport in horizontal wellores", SPE Drilling \& Completion, vol. 14, pp. 196-200, 1999.

[4] Y. Masuda, Q. Doan, M. Ogutoreli, S. Nagawa, T. Yonezawa, A. Kobayashi, and A. Kamp, Critical Cuttings Transport Velocity in Inclined Annulus: Experimental Studies and Numerical Simulation, at the $2000 \mathrm{SPE} /$ Petroleum Society of CIM International Conference, 2000, pp. 1-12.

[5] J. Li, and S. Walker, Sensitivity Analysis of Hole Cleaning Parameters in Directional Wells, at the 1999 SPE/ICoTA Coiled Tubing Roundtable, 1999, pp. 1-10.

[6] M.E. Ozbayoglu, A. Saasen, M. Sorgun, and K. Svanes, Effect of Pipe Rotation on Hole Cleaning for Water-Based Drilling Fluids in Horizontal and Deviated Wells, at IADC/SPE Asia Pacific Drilling Technology Conference and Exhibition, 2008, pp. 1-11.

[7] Z.S. Qiu, J.F. Xv, W.A. Huang, L. Jiang, and L.X. Yu, "The Experimental Facility of Cuttings Transport and Borehole Stability in Deep Water Drilling", China Patent 200910250325.4, December 4, 2009.

[8] S.G. Valluri, S.Z. Miska, R. Ahmed, M. Yu, and N.E. Takach, Experimental Study of Effective Hole Cleaning Using "Sweeps" in Horizontal Wellbores, at the 2006 SPE Annual Technical Conference and Exhibition, 2006, pp. 1-13.

[9] R.M. Ahmed, and N.E. Takach, "Fiber sweeps for hole cleaning", SPE Drilling \& Completion, vol. 24, pp. 564-572, 2009.

[10] E. Cheung, N. Takach, E. Ozbayoglu, R. Majidi, and B. Bloys, Improvement of Hole Cleaning Through Fiber Sweeps, at the SPE Deepwater Drilling and Completions Conference, 2012, pp. 1-11.

[11] S.S. Okrajni, and J.J. Azar, "The effects of mud rheology on annular hole cleaning in directional wells", SPE Drilling Engineering, vol. 1, pp. 297-309, 1986.

[12] A. Saasen, Hole Cleaning During Deviated Drilling-the Effects of Pump Rate and Rheology, at the 1998 SPE European Petroleum Conference, 1998, pp. 161-167.
[13] J.M. Peden, J.T. Ford, and M.B. Oyeneyin, Comprehensive Experimental Investigation of Drilled Cuttings Transport in Inclined Wells Including the Effects of Rotation and Eccentricity, at the 1990 European Petroleum Conference, 1990, pp. 394-405.

[14] N.P. Brown, P.A. Bern, and A. Weaver, Cleaning Deviated Holes: New Experimental and Theoretical Studies, at the 1989 SPE/IADC Drilling Conference, 1989, pp. 171-180.

[15] T.R. Sifferman, and T.R. Becker, "Hole cleaning in full-scale inclined wellbores", SPE Drilling Engineering, vol. 7, pp. 115-120, 1992.

[16] R.A. Sanchez, J.J. Azar, A.A. Bassal, and A.L. Martins, "Effect of drillpipe rotation on hole cleaning during directional-well drilling", SPE Journal, vol. 4, pp. 101-108, 1999.

[17] H.G. Wang, X.S. Liu, H.Q. Li, and G. Ding, "An experimental study of transport of drilling cuttings in a horizontal well", Acta Petrolei Sinica, vol. 16, pp. 125-132, 1995.

[18] A.A. Bassal, "The Effect of Drillpipe Rotation on Cuttings Transport in Inclined Wellbores", University of Tulsa, Tulsa, Oklahoma, USA, 1995.

[19] A.L. Martins, C.H.M. Sa, A.M.F. Lourenco, and W. Campos, Optimizing Cuttings Circulation in Horizontal Drilling, at the international Petroleum Conference and Exhibition, 1996, pp. 295304.

[20] S. Walker, and J. Li, The Effects of Particle Size, Fluid Rheology, and Pipe Eccentricity on Cuttings Transport, at the 2000 SPE /IcoTa Coiled Tubing Roundtable, 2000, pp. 1-8.

[21] M.E. Ozbayoglu, Z.M. Stefan, Troy Reed, and N. Tahach, Analysis of the Effects of Major drilling Parameters on Cuttings Transport Efficiency for High-Angle Wells in Coiled Tubing Drilling Operations, at the SPE /IcoTa Coiled Tubing Conference and Exhibition, 2004, pp. 1-8.

[22] M.J. Yu, E.T. Nicholas, R.N. David, and M.S. Maher, An Experimental Study of Hole Cleaning Under Simulated Downhole Conditions, at the 2007 SPE Annual Technical Conference and Exhibition, 2007, pp. 1-14.

[23] S. A. Mirhaj, S. R. Shadizadeh, and M. Fazaelizadeh, Cuttings Removal Simulation for Deviated and Horizontal Wellbores, at the $15^{\text {th }}$ SPE Middle East Oil \& Gas Show and Conference, 2007, pp. $1-6$.

[24] M. Sorgun, Modeling of Newtonian Fluids and Cuttings Transport Analysis in High Inclination Wellbores with Pipe Rotation, $\mathrm{PhD}$ Middle east Technical University, Ankara, Turkey, 2010.

[25] M.Q. Duan, S. Miska, M.J. Yu, N. Takach, and R. Ahmed, "Transport of small cuttings in extended reach drilling", SPE Drilling \& Completion, vol. 23, pp. 258-265, 2008.

[26] M.Q. Duan, S. Miska, M.J. Yu, N. Takach, R. Ahmed, and C. Zettner, "Critical conditions for effective sand-sized solids transport in horizontal and high-angle wells", SPE Drilling \& Completion, vol. 24, pp. 229-238, 2009.

[27] B.V. Loureiro, R.S. de Paula, M.B. Serafim, and A.L. Martins, Experimental Evaluation of the Effect of Drillstring Rotation in the Suspension of a Cuttings Bed, at the SPE Latin American \& Caribbean Petroleum Engineering Conference, 2010, pp. 1-14.

[28] T. Hemhill, and J.C. Rojas, Drilling Fluid Sweeps: Their Evaluation, Timing, and Applications, at the SPE Annual Technical Conference, 2002, pp. 1-7.

[29] R.V. Bulgachev, and P. Pouget, New Experience in Monofilament Fiber Tandem Sweeps hole Cleaning Performance on Kharyaga Oilfield, Timan-Pechora Region of Russia, at the 2006 SPE Russia Oil and Gas Technical Conference, 2006, pp. 1-11.

[30] M.E. Ozbayoglu, A. Saasen, M. Sorgun, and K. Svanes, "Critical fluid velocities for removing cuttings bed inside horizontal and deviated wells", Petroleum Science and Technology, vol. 28, pp. 594-602, 2010

[31] V.C. Kelessidis, and G.E. Mpandelis, Hydraulic Parameters Affecting Cuttings Transport for Horizontal Coiled Tubing Drilling, at the $7^{\text {th }}$ National Congress on Mechanics, 2004, pp. 1-9.

[32] Y. Masuda, Q. Doan, M. Ogutoreli, S. Nagawa, T. Yonezawa, A. Kobayashi, and A. Kamp, Critical Cuttings Transport Velocity in Inclined Annulus: Experimental Studies and Numerical Simulation, at the 2000 SPE/Petroleum Society of CIM International Conference, 2000, pp. 1-12.

[33] H.I. Bilgesu, M.W. Ali, K. Aminian, and S. Ameri, Computational Fluid Dynamics (CFD) as a Tool to Study Cutting Transport, at the SPE Eastern Regional Meeting, 2002, pp. 1-4. 
[34] H.I. Bilgesu, N. Mishra, and S. Ameri, Understanding the Effects of Drilling Parameters on Hole Cleaning in Horizontal and Deviated Wellbores Using Computational Fluid Dynamics, at the SPE Eastern Regional Meeting, 2007, pp. 1-7.

[35] M.W. Ali, A Parametric Study of Cuttings Transportation in Vertical and Horizontal Well Using Computational Fluid Dynamics (CFD), M.S. thesis, West Virginia University, West Virginia, U.S.A, 2002.

[36] N. Mishra, Investigation of Hole Cleaning Parameters Using Computational Fluid Dynamics in Horizontal and Deviated Wells, M.S. thesis, West Virginia University, West Virginia, U.S.A, 2007.

[37] M. Li, Z.M. Wang, B.Y. Hao, Z.Q. Wang, and Y.K. Hong, "The effect of drill pipe rotation on hole cleaning in extended reach wells", China Petroleum Machanery, vol. 37, pp. 34-37, 2009.

[38] M. Li, Y.F. Jv, Z.Q. Wang, B.Y. Hao, and Y.K. Hong, "Simulation on the effect of drill pipe rotation on hole cleaning in extended reach horizontal wells", West-china Exploration Engineering, vol. 5, pp. 51-54, 2010.

[39] H.Y. Sun, "Study on cuttings bed removing tool design and flow field simulation", China Petroleum Machinery, vol. 37, pp. 38-41, 2009.

[40] F. Chen, Q.F Di, P.B Yuan, W.C. Wang, J.L. Yao, Y.Q. Zhou, and G.X. Zhai, "Mechanism of an effective hydroclean drill pipe for hole cleaning", ACTA Petrolei Sinica, vol. 33, pp. 298-303, 2012.

[41] A.A. Gavignet, and I.J. Sobey, "Model aids cuttings transport prediction", $J P T$, vol. 41, pp. 916-921, 1989.

[42] M. Santana, A.L. Martins, and A.S. JR, Advances in the Modeling of the Stratified Flow of Drilled Cuttings in High Angle and Horizontal Wells, at the international Petroleum Conference and Exhibition, 1998, pp. 1-8.

[43] A.L. Martins, and C.C. Santana, Evaluation of Cuttings Transport in Horizontal and Near Horizontal Wells - A Dimensionless Approach, at the Second Latin America Petroleum Engineering Conference, 1992, pp. 155-161.

[44] D. Nguyen, and S.S. Rahman, A Three-Layer Hydraulic Program for Effective Cuttings Transport and Hole Cleaning in Highly Deviated and Horizontal Wells, at the 1996 IADC/SPE Asia Pacific Drilling Technology, 1996, pp. 163-173.

[45] A.L. Martins, M.L. Santana, and E.F. Gaspari, "Evaluating the transport of solids generated by shale instabilities in erw drilling", SPE Drilling \& Completion, vol. 14, pp. 254-259, 1999.

[46] A.M. Kamp, M. Rivero, Layer Modeling for Cuttings Transport in Highly Inclined Wellbores, at the 1999 SPE Latin American and Caribbean Petroleum Engineering Conference, 1999, pp. 1-12.

[47] J.T. Ford, M.B. Oyeneyin, J.M. Peden, M.B. Larrucia, and D. Parker, "A new MTV computer package for hole-cleaning design and analysis", SPE Drilling \& Completion, vol. 11, pp. 168-172, 1996.

[48] R.K. Clark, and K.L. Bickham, A Mechanistic Model for Cuttings Transport, at the SPE 69th Annual Technical Conference and Exhibition, 1994, pp. 139-153.

[49] T.I. Larsen, A.A. Pilehvari, and J.J. Azar, Development of a New Cuttings Transport Model for High-Angle Wellbores Including Horizontal Wells, at the SPE Rocky Mountain Regional/Low Permeability Reservoir Sympoelum, 1993, pp. 331-342.

[50] Y.J. Luo, P.A. Bern, B.D. Chambers, Flow-Rate Predictions for Cleaning Deviated Wells, at the 1992 IADC/SPE Drilling Conference, 1992. pp. 367-366.

[51] H. Cho, S.N. Shah, and S.O. Osisanya, A Three-Layer Modeling for Cuttings Transport with Coiled Tubing Horizontal Drilling, at the 2000 SPE Annual Technical Conference and Exhibition, 2000, pp. $1-14$.

[52] Z.M. Wang, and Z. Zhang, "A model for two-layer cutting transport in horizontal wells", Journal of the University of Petroleum, vol. 28, pp. 63-66, 2004.
[53] H. Cho, S.N. Shah, and S.O. Osisanya, Effects of Fluid Flow in a Porous Cuttings-Bed on Cuttings Transport Efficiency and Hydraulics, at the 2001 SPE Annual Technical Conference and Exhibition, 2001, pp. 1-14.

[54] V.C. Kelessidis, and G.E. Mpandelis, Flow Patterns and Minimum Suspension Velocity for Efficient Cuttings Transport in Horizontal and Deviated Wells in Coiled-Tubing Drilling, at the SPE/IcoTA Coiled Tubing Conference, 2003, pp. 1-16.

[55] H. Cho, S.N. Shah, and S.O. Osisanya, "A three-segment hydraulic model for cuttings transport in coiled tubing horizontal and deviated drilling", JCPT, vol. 41, pp. 32-39, 2002.

[56] Y. Li, N. Bjorndalen, and E. Kuru, "Numerical modeling of cuttings transport in horizontal wells using conventional drilling fluids", JCPT, vol. 46, pp. 9-14, 2007.

[57] S.C. Suzana, S. Sidney, and A.B. Sergion, Simulation of Transient Cuttings Transportation and ECD in Wellbore Drilling, at the 2008 SPE Europe/EAGE Annual Conference, 2008, pp. 1-9.

[58] Z.M. Wang, Z. Zhang, "A two-layer time-dependent model for cuttings transport in extended- reach horizontal wells", Journal of Hydrodynamics, vol. 19, no. 5, pp. 677-681, 2004.

[59] Z.M. Wang, Y.J. Zhai, X.N. Hao, X.L. Guo, and L.L. Sun, Numerical Simulation on Three Layer Dynamic Cuttings Transport Model and Its Application on Extended Well Drilling, at the IADC/SPE Asia Pacific Drilling Technology Conference and Exhibition, 2010, pp.1-10.

[60] Q. T. Doan, M. Oguztoreli, Y. Masuda, T. Yonezawa, A. Kobayashi, S. Naganawa, and A. Kamp, "Modeling of transient cuttings transport in underbalanced drilling (UBD)", SPE Journal, vol. 8, pp. 160-170, 2003.

[61] G. Espinosa-Paredes, R. Salazar-Mendoza, and O. Cazarez-Candia, "Averaging model for cuttings transport in horizontal wellbores", Journal of Petroleum Science and Engineering, vol. 55, pp. 301316, 2007.

[62] R. Salazar-Mendoza, and G. Espinosa-Paredes, "A three-region hydraulic model for solid- liquid flow with a stationary bed in horizontal wellbores", Journal of Petroleum Science and Engineering, vol. 27, pp. 1033-1043, 2009.

[63] M.E. Ozbayoglu, M. Sorgun, A. Saasen, and K. Svanes, "Hole cleaning performance of light- weight drilling fluids during horizontal underbalanced drilling", JCPT, vol. 49, pp. 21-26, 2010.

[64] D.W. Zhao, C.Y. Dong, Q. Zhang, and X.W. Fu, "Critical velocity model for grain incipient motion in consideration of the randomness of grain location", Journal of the University of Petroleum, vol. 28, pp. 59-66, 2004.

[65] M. Mohammadsalehi, and N. Malekzadeh, Optimization of Hole Cleaning and Cuttings Removal in Vertical, Deviated and Horizontal Wells, at the SPE Asia Pacific Oil and Gas Conference and Exhibition, 2011, pp. 1-8.

[66] Study Group, "Cuttings Transport with Drillstring Rotation", presented by B. Paul, Schlumberger, pp. 1-13.

[67] B. Robert, "Cuttings Bed Removal Tool", U. S. Patent 2007/0278011, December 6, 2007.

[68] S. George, "Cutting Bed Impeller", U.S. Patent 6, 223, 840, May 1, 2001.

[69] R. Ahmed, M. Sagheer, N. Takah, R. Majidi, M. J Yu, and S. Miska, Experimental Studies on the Effect of Mechanical Cleaning Devices on Annular Cuttings Concentration and Applications for Optimizing ERD Systems, at the SPE Annual Technical Conference and Exhibition, 2010, pp. 1-13.

[70] A.L. Martins, M.B. Villas-Boas, H.S. Taira, A.F. Aragão, R.A.F. Amorim, Y.D. Galeano, A. Bove, and A.T.A. Waldmann, Real Time Monitoring of Hole Cleaning on a Deepwater Extend Well, at the SPE/IADC Drilling Conference, 2003, pp. 1-7.

This is an open access article licensed under the terms of the Creative Commons Attribution Non-Commercial License (http://creativecommons.org/licenses/by-nc/3.0/) which permits unrestricted, non-commercial use, distribution and reproduction in any medium, provided the work is properly cited. 